\title{
Study on the Social Order of Cross-border Ethnic Groups
}

\author{
Zhaofei Fan
}

Liupanshui Normal University, Guizhou, Liupanshui, 553000

\author{
Keywords: Cross-border Ethnic Groups, Social Order, Economy Status
}

\begin{abstract}
The social development and stability of the border areas are the basic requirements of the national stability and unity. The factors that affect the social development and stability of the border areas are multifaceted. However, under the conditions of peace, economic development and national policy are two important factors. Cross-border ethnic groups living in different countries, poverty and backwardness is the universal social characteristics of cross-border nationalities. On the surface, the borders of the border people, but in fact encourage or stimulate the border side of the driving force is poor habitat. Therefore, the study of cross-border national social order is not only an academic problem, it is an urgent political and national issues, not only to promote ethnological anthropology and other disciplines in-depth development of academic value, but also has a strong social stability to maintain the reality significance.
\end{abstract}

\section{Introduction}

A cross-border nation is the same nation living on both sides of the border. The border between the states is not consistent with the geographical boundaries of the nation. Cross-border ethnic groups are the product of the development of national history and the modern international political function. In today's world, the same nation living in a number of countries, a country, including a number of ethnic groups, and a number of ethnic cross-border phenomenon is quite common. Although the cross-border peoples belong to different countries, there are different countries and national values, but because of the formation of the process of ethnicity, the common history and culture, still determines the cross-border nationalities as a whole and part of the differences and the basic characteristics of strong national identity. At the same time, with the influence of politics in modern times on the social life of people, the political, economic and cultural interaction between ethnic groups is becoming stronger and stronger. Cross-border ethnic groups in different countries are affected by different countries of the system and other factors and all aspects of the interaction is more obvious. This is the theoretical basis for cross - border ethnic research in this paper.

\section{Analysis of the Order of Cross - border Ethnic Groups}

The Yao nationality of the border between Yunnan and Vietnam, the earliest living in the same area, and later because of migration or border changes and other reasons were living in the two adjacent countries, but its language and culture are basically the same. Ethnic identity is the subjective choice of social members, but this subjective consciousness, behavior is often subject to historical and cultural factors. In the border area of Yunnan and Vietnam, the ethnic group of Yao nationality is an important factor influencing its ethnic identity. The origin of the family not only reflects its origins, migration, evolution and development process, but also the historical memory and emotion formed by the ethnic groups, but also directly reflects the self-consciousness of this group and has an important influence on the ethnic identity consciousness and concept. On the side of the border, cultural groups also have my group and his group of consciousness. Yao has since ancient times, "Yao Yao Yao, toward the DPRK" concept, never obey the jurisdiction of the court. From the beginning of the Ming Dynasty, the central government repeatedly sent troops to suppress the Yao nationality. Yao and Han were carried out for hundreds of years between the war, Guangxi Dayao Gorge Yao uprising failed, the Yao was unable to organize forces against the court, in order to avoid the Han to kill, forced to continue to the mountains in the concession, No mountain does not become Yao "distribution pattern. Living in the mountains, the land is barren, Yao can only rely on 
hunting and fishing to maintain life. As the Yao long-term as a companion, so, in the early days, the Yao called "corrupt tribe", intended to be the same kind of animals and animals. Living in the mountains of the Yao people never and the mountains outside the Han and Later, the mountains around the Han merchants gradually shoulder oil, salt and other daily necessities and other daily necessities to the mountains and Yao exchange of leather, Yao Han began to gradually have some exchanges, so in the early days, the Yao people are afraid of the Han psychological. Investigation also listens to Yao villagers also said that childhood often listen to the story of the elders speak old man, very afraid. If the children do not listen, adults use the "old man to" like to scare the child, before the children are not afraid of school "old man" the word, the mountains of the Han have a strong fear, if Some people come to the village, the villagers sometimes quickly escape.

\section{Cultural Borderland's Borderland Consciousness and its Borderland Life Practice}

In the border area of Malipo bordering Vietnam, it is the main battlefield of the Sino-Vietnamese war. The war has brought many devastating effects to the local people, not only deteriorating the living environment of the border people, but also the border detonators Disability. The region has always been a national poverty-stricken counties, the war makes hundreds of thousands of acres of arable land destroyed, soil erosion area of up to hundreds of square kilometers, landslides, debris flow and other texture disasters occur frequently, to the original lack of economic development channels, no economic income, Lack of food and clothing poor people suffer more difficulties. Coupled with the Sino-Vietnamese war after the Chinese troops officers and men in the border line 500 meters away from the vertical place of nearly 1 million landmines, as well as troops left under the firearms and ammunition, explosives, although the local government organized two large-scale demining There are still dozens of square kilometers of land is minefield, to the people of the lives and property caused great harm.

Before the establishment of the modern state, in fact until 1949, due to the state of the border, the management of society is not strict, so the border on both sides of the transnational marriage is basically no big legal problems. "Since the 20th century, 40 years, Vietnam is a long time in a war environment. First of all, 50 years of resistance to war in the 50's Vietnam has not yet emerged from the colonial rule, Ho Chi Minh leader of the liberation of Vietnamese Vietnam, China and Vietnam began to develop "comrades brother" intimate relationship during this period, China's implementation of the "one five" plan and socialist transformation, the trial of agricultural production cooperatives in the vast border of rural areas, agricultural cooperation, the Great Leap Forward and the people's commune movement in full swing this period more and more married Chinese women, China to their Legal status, status given to the investigation that the 50's married Vietnamese women in the 1950s, in the local can account, and issued a "residence permit", China to give special care.

\section{The Method of Maintaining the Social Order of the Ethnic Groups}

The cross-border national problem is a double-edged sword, which has a positive effect on the stability and development of the border areas in many respects, but the increase in the possibility of conflict between the state and the cross-border peoples. Adhere to the cross-border peoples of the two countries you come to me on the one hand is the relationship between simple relatives, family source, blood as the most natural and the most solid relationship between the bonds, the division of the different countries in the same cultural groups linked together, This way of communication to form a cross-border national social relations, so as to establish a social adaptability, this adaptability through social and cultural exchanges, transnational marriage, ethnic consciousness and so on. On the other side, cross-border ethnic exchanges will continue to expand in terms of the degree of economic development and social development in terms of intensity and breadth. When the economy is prosperous and resources in various markets can flow quickly and effectively, The intercultural exchanges will be more frequent. Cross-border peoples are pursuing on both sides of the vast border line in order to maximize their interests. The interests that are formed in this process 
are based on mutual trust and mutual benefit. Therefore, the results will, in turn, promote cross- A positive interaction between emotions.

Cross-border ethnic groups from the family history, language, religious beliefs and customs point of view, is undoubtedly a unique social characteristics of the cultural groups, due to the close ties between history, geography, and the coexistence of ethnic culture, making the neighboring countries Cross-border peoples have mutual recognition of the historical origins, to maintain roughly the same customs, with the language of the same; in the economic culture and because of geography, marriage and affinity formed by the contacts and contacts are inseparable, and no Which is interrupted by the division of the state borders. The same group of cross-border is the product of the border, although the separation of the two countries but its internal ethnic identity will not be divided.

Subjective cross-border peoples retain a common sense of cultural groups, while their own political geography of the right center has its own different sense of identity. Because of the differences in political identity, they each belong to the citizens of the host country and hold different national identities. At the same time, they have gradually formed different national consciousness and emotions by the influence of the culture of the host country. This has deepened the relationship between the cross- the national identity of the country, this clear recognition of the country rooted in the borders of the political field.

Due to the remote location of the border, border areas and the outside world to the material and cultural information exchange is very difficult, closed state so that less of the modern civilization of the fire. The low level of productivity and economic level of the local education has been seriously affected, the people's cultural level is generally low, the concept of backward; some border people will only say that the national language, in addition to the town outside the market less contact with the outside world, Most people have not heard of the word "well-off society", the geographical and cultural edge not only make this group lack of economic sources channels, market competitiveness, but also make them gradually lost the expectations of changing the status quo. They know that the low impact in social life is difficult to rely on their own power to change the status quo, and the national policy has not really enjoy, so their recognition of the state is bound to weaken to some extent.

The state to develop preferential policies is not it should not be in accordance with the national division to give preferential policies, because such a one-size-fits-all approach can not work, the same preferential policies for the same nation, life is not good, life is poor, Substantial effect. And the national preferences for regional concessions will be able to make the policy more targeted, compared to the effect will be better? Living in the same area within the different ethnic groups, their living conditions are basically the same, with Common difficulties and problems, with the same needs, to regional as a preferential policy standard, the effect may be more powerful. Because the implementation of the policy should be consistent with the objectives of the implementation of the target, they accepted.

\section{Conclusion}

For groups such as ethnic origin, language and culture, such as consistency and political and national ownership inconsistency, the state should fully understand its characteristics of universality and particularity in formulating policies, and the policy can not be across the board. To the maximum extent to listen to the voice of the people, the interests of the demands of the real life environment, based on the combination of its characteristics as a cross-border ethnic groups, policy development and implementation not only to the maximum extent possible to meet the actual needs of the border, Of the poor living conditions, so that people in the frontier areas of the country can gradually narrow the gap between the living standards of the people of the Mainland; the same time, the policy should meet the needs of the border people with cross-border ethnic minorities and the same ethnic groups, National benign interaction under the premise of illegal cross-border activities, so that national defense front-line areas to sustainable security, peace and stability. Only by formulating the policy of adaptation, making good use of these policies and making full use of the 
Huimin policy effect can we gradually build the "spiritual frontier" in practice so as to provide strong support for the consolidation and development of our border areas.

\section{References}

[1] Li Chunxia. Public knowledge: "cultural ethnic group"/"national nation" and citizens [J]. Journal of Northern University for Nationalities. 2010 (04)

[2] Gu Xiaosong, Liang Bingmeng. The resignation of normalization-60 years of Sino-Vietnamese relations review and outlook [J]. Southeast Asia aspect, 2010 (01)

[3] Xiao Bin. Two duals of citizenship and national identity [J]. Journal of Wuhan University 2010 (01)

[4] Han Zhen. On national identity, national identity and cultural identity - based on historical philosophy analysis and thinking [J]. Journal of Beijing Normal University, 2010 (01)

[5] He Bo. Tradition and Choice: China's Border Minority "China Identity" [J]. Ideological Front, 2009 (06) 